\title{
Capstone project challenges: How industry sponsored projects offer new learning experiences
}

\section{Dr. Carrie Steinlicht, South Dakota State University}

Dr. Carrie Steinlicht is an Asst. Professor of Operations Management. She has directed many Capstone projects with Industry partners for students in Manufacturing Engineering Technology and Operations Management. She has several years of industry experience as an advanced development engineer and has served as a consultant to industry for over 10 years.

\section{Prof. Byron G. Garry, South Dakota State University}

Byron Garry is an Associate Professor of Electronics Technology and the Undergraduate Program Coordinator of the Department of Construction \& Operations Management, in the Jerome J. Lohr College of Engineering at South Dakota State University. His research interests are in the areas of student learning, assessment of student learning and dissemination of the Scholarship of Teaching and Learning. 


\section{Capstone Project Challenges: How Industry Sponsored Projects Offer New Learning Experiences}

\section{Introduction}

There has been an ongoing debate on the value of industry sponsored projects as learning tools in the curriculum. While most researchers agree that these projects provide excellent learning experiences, some believe that methods such as case studies are a much better choice overall than industry sponsored projects because they are less work and do not have the uncertainties that can be associated with industry sponsored projects ${ }^{1}$. Students in the Manufacturing Engineering Technology (MNET) and Operations Management (OM) programs at South Dakota State University have been engaged in industry sponsored projects for several years. Students, faculty, and industry sponsors have benefited from the experiences associated with these industry sponsored projects. In this study, the authors have more closely examined the nature of these experiences and the primary learning experiences of the students participating in these projects.

\section{Background}

ABET Criterion 5 Curriculum section states that "Baccalaureate degree programs must provide a capstone or integrating experience that develops student competencies in applying both technical and non-technical skills in solving problems." ${ }^{2}$. A short search of ASEE Conference papers variously defines the goal of the Capstone experience is "to integrate the engineering and management disciplines into a single comprehensive educational experience", "to provide a bridge for the students to cross between the academic world on one side and the technical professional world on the other", to "provide an extensive platform to practice engineering design and to facilitate the integration of what students have learned throughout their curriculum", "to better prepare graduates for engineering practice", and "to demonstrate their abilities to potential employers"?

Shuman et al., broke down the ABET Student Outcomes a-k into the categories of hard skills and professional skills. The Student Outcomes that represent professional, or 'soft', skills were

- an ability to function on multi-disciplinary teams

- an understanding of professional and ethical responsibility

- an ability to communicate effectively

- the broad education necessary to understand the impact of engineering solutions in a global, economic, environmental, and societal context

- a recognition of the need for, and an ability to engage in lifelong learning, and

- a knowledge of contemporary issues ${ }^{8}$

Shuman, et al. in their study of professional skills concluded "Although not necessarily taught in the traditional lecture format, these [professional] skills can certainly be mastered as part of a modern engineering education format that utilizes active and cooperative learning, recognizes differences in learning styles, and is cognizant of teaching engineering in its appropriate context" ${ }^{\prime 8}$. Soft skills are necessary for professional success. These skills are related to the execution of communicating, managing time, negotiating, writing, listening, reading, presenting, 
problem solving, and decision-making. People are said to rise in an organization because of hard skills, but fail because they lack soft skills ${ }^{9}$. The right mix of hard and soft skills is important and should be included as a competency in engineering and technology education.

Sheppard, et al. studied current engineering education practice at several major universities, and found that the primary emphasis on acquisition of technical knowledge is not adequately preparing students for professional practice. In their review of education literature, they break down the types of knowledge used by engineers into seven types of knowledge. Undergraduate education is focused on four of those types: Theoretical Tools, Fundamental Design Concepts, Criteria and Specifications, and Qualitative Data. They classify professional knowledge, or soft skills, into three additional types: Practical Considerations, Process-Facilitating Strategies, and Contextual and Normative Knowledge ${ }^{10}$.

The description of the integrating experiences required by the ABET criteria suggests that they involve some type of project work which is ideal for developing soft skills in students ${ }^{11}$. Project work or case studies have also been associated with deep learning which promotes wellstructured high-level outcomes and better, long term results. Boyce, Williams, Kelly, and Yee ${ }^{12}$ show how project work incorporates the 4 characteristics of deep learning as described by Biggs $^{13}$. First, projects must have motivational context which is achieved through applying knowledge to actual or simulated scenarios. The students become more engaged in projects that have a dimension of reality. The second characteristic is active learning which encourages judgment on the part of the students to resolve ambiguity and uncertainty, essential skills in decision making. The third characteristic is interaction with others. Projects are ideal vehicles for interaction because they often require teamwork where students must defend ideas, listen to others, ask questions, discuss solutions, and present findings. The last characteristic is a knowledge base. In project work, this knowledge base is developed further as students take concepts and apply them placing the ideas into practice to solve problems ${ }^{12}$.

The ABET criteria, however, does not prescribe the method for providing these integrating experiences. Various programs use differing methods that can include theoretical projects, case studies, independent projects, as well as industry sponsored or client based projects. Each of these can be effective means of providing integrating experiences. Theoretical projects and case studies are the least unpredictable of the types of projects. These types of projects are completely under the control of the instructor and any overwhelming ambiguity or uncertainty is easily resolved with minimal effort. The most unpredictable type of project is the client or industry sponsored projects.

The uncertainties inherent in industry sponsored projects include things such as ambiguity, delays, communication issues, potential scope changes, company specific constraints, and differing personalities. The constraints of industry sponsored projects are often unique to the situation and these constraints may change mid-stream. These project characteristics make industry sponsored projects difficult for both the student and the instructor. Students can get frustrated or overwhelmed under these situations ${ }^{1}$. Instructors spend a large amount of time soliciting, selecting, and coordinating projects then find themselves adjusting to situations they cannot control. Students must ask more questions and develop alternate solutions for 
consideration. Students cannot just assume certain conditions exist; they must confirm the existence. This requires the use of good communication skills.

Industry sponsored projects, however, often provide context specific challenges that are not easily duplicated in a more structured academic environment. The collaborative nature of industry sponsored projects is instrumental in the development of skills such as reporting, problem analysis, small group collaboration, communication, critical thinking, teamwork, and problem solving. Participation in industry sponsored projects is sought by recruiters because they signify development of these skill sets ${ }^{1}$.

Industry sponsored projects are also connected to a greater dynamic system that offers students insight into how all parts of the system must work together to provide the greatest benefit. The situation is real and success has an impact on a real company. If implementation is part of the project, the students can also witness how the results reach into other parts of the organization. System dynamics are more easily illustrated within a real organization and provide better learning experiences regarding systems. Students who have been exposed to the concepts and practice of systems thinking in a course before reaching the Capstone course can take advantage of their prior learning as they approach the Capstone project ${ }^{14}$. In the Capstone project itself, students apply deep learning experiences rather than surface learning techniques and are more engaged in the process of problem solving ${ }^{15}$. It has been shown that students involved in industry sponsored projects appreciate the integration of soft and hard skills in these types of projects ${ }^{16}$. They also highly value working within a real organization ${ }^{1}$.

Industry viewpoints

The author's experience with Capstone projects agrees with the findings of Heybruck, in reference to university-industrial relationships, that faculty teaching Capstone courses are always doing a balancing act and serving two parties. On the students side, industry exposure helps the students to increase their knowledge of the engineering work world, to become aware of global, societal, contemporary issues such as ethics, technology, outsourcing, diversity, to hone their professional development skills and professional behaviors, and to expand their knowledge of the engineering profession in hopes to create retention both in college and in the industry. On the industry side, exposure to students helps them to get to know the top performing students, to establish relationships with faculty, to influence the undergraduate curriculum and help invest in the future workforce, and to solve engineering problems at a low cost while previewing potential applicants for future job openings ${ }^{17}$.

John Roundhill, then a vice president of The Boeing Company addressing the 2001 Engineering Deans Institute, proposed a list of desired attributes of engineers. These include a good understanding of engineering science fundamentals, a good understanding of design and manufacturing processes, good communication skills, a multi-disciplinary, systems perspective, a basic understanding of the context in which engineering is practiced, and a profound understanding of the importance of teamwork ${ }^{18}$. An annual survey of manufacturing educators and professionals finds that co-operative education and internships continue to be the overwhelming priority for practitioners. In a complimentary sense, project and design work is favored by academics, and practitioners second that opinion. Laboratory and teamwork also 
receive special mention. In total these illustrate the importance of education that includes exploration in the lab, through projects, and in the workplace ${ }^{19}$.

The knowledge and skills needed for industry practice are varied and extensive. ASEE has begun a multi-year study entitled Transforming Undergraduate Education in Engineering (TUEE). The first phase brought together academics and industry representatives in a workshop to discuss how undergraduate education meets the needs of industry's needs for graduates currently. The report states that industry values a solid foundation in math and science and that students must have a sufficient grasp of these fundamentals to understand the dimensions of a problem without relying on models. Less well-defined but necessary, in the view of many workshop participants, are good communication skills, persistence, curious learning capability, drive and motivation, economics and business acumen, high ethical standards, critical thinking, and willingness to take calculated risks ${ }^{20}$.

The TUEE Phase I workshop and follow-up developed a list of 36 Knowledge, Skills, and Abilities (KSAs) traits. The study report indicates that while a foundation in basic knowledge is important, students must also include programming, systems thinking, ability to use relevant tools, as well as less defined skills such as good communication skills, persistence, curious learning capability, drive and motivation, economics and business acumen, high ethical standards, critical thinking, and willingness to take calculated risks. Five of these traits were identified as targets for emphasis in capstone courses. These include communication skills; the ability to identify, formulate, and solve problems; systems integration; economics and business acumen; and project management skills ${ }^{20}$. Of these traits, several can be classified as soft skills which are often lacking in undergraduate studies ${ }^{21}$.

Study

The MNET and OM programs have been developed using ABET Accreditation criteria for accrediting Engineering Technology programs and therefore have a Capstone course designed to provide students these integrating experiences. The faculty in the department have been exploring the learning experiences of the students in these courses with the intent of developing courses that provide the best learning experiences for the students.

In the past, research was undertaken to see if there are any prior experiences or attitudes that students bring into the senior Capstone course that correlate with group Capstone project success. A variety of assessment techniques were used to obtain both quantitative measurements and qualitative indicators in an attempt to find common factors students have coming in to the course sequence that affect how well the projects succeed. Analysis of the data found that student groups who, on average, are satisfied with their preparation in the area of the soft skills like teamwork, commitment to quality, and project management tended to do better on their projects $^{22}$. Other assessment information shows that students enjoy working with real companies on real projects that make a difference in the operations of the companies. Students feel challenged and more engaged in problem solving than in other academic coursework. One question that has not yet been answered is the nature of the learning experienced in the current course design in each of the areas of knowledge. 
The classification of professional skills into three types of knowledge by Sheppard, et al., Practical Considerations, Process-Facilitating Strategies, and Contextual and Normative Knowledge, provided the authors with a basis for their study. A further description of these types of knowledge is now necessary. Practical Considerations are considered tacit knowledge, typically learned on the job. These include rules of thumb and design considerations that professionals in industry follow as they do their design work. Process-Facilitating Strategies include the knowledge of project management, teamwork, leadership, and communication. Contextual and Normative Knowledge are the personal, professional, and cultural norms and behaviors that are expected in the industry workplace ${ }^{10}$.

Research Question

Based upon previous experience in the course and anecdotal evidence, we expect that the capstone experience using industry sponsored projects would result in student learning outcomes related both to technical and non-technical skills. The question to be researched was "Is there a difference in student's perception of the importance of types of skills used in the capstone course?" We do not have a large enough data set to apply statistical analysis to the results, so a frequency chart will display the results.

\section{Research Design}

For this study, the authors designed a survey to determine in what categories of knowledge students felt they had experienced the greatest challenges in the course and in what categories the students felt they had gained the most knowledge. The survey was administered to students in the Capstone course during the Fall 2013 semester. The Capstone course was a 1 credit course that is held concurrently with another Project Management course $(2 \mathrm{cr}$.). These two courses were coordinated so that the students could use one project for both classes. The class consisted of 17 students. These students were engaged in six different capstone projects with six different industry sponsors at four different companies located in the region. The projects were originally solicited by the instructor of the capstone course and screened to provide students with the best opportunities for practicing their discipline in a work environment. Student groups consisted of 2-3 student members that self-selected projects. Students generally were able to participate on a project that was either their first or second choice which improved their motivation to complete the tasks successfully. The students were surveyed 2 weeks prior to the end of the semester and prior to the end of most of the projects. Students were given a written survey during one class period. Students were told that they did not have to participate. All but one student participated in the survey.

The student projects included researching and costing a new shipping crate system, developing a new process that would reduce custom product quoting time by $50 \%$, developing a new material handling process for scrap iron reclaim materials in a foundry, improving product line performance to meet takt for a high volume fishing equipment manufacturer, developing and implementing a new inventory management system for a growing ag equipment manufacturer, and developing a way to implement an OEE system for a metal fabrication process that the customer currently had no metrics for. The projects were all time intensive. Students had to complete their projects within a single semester and the time commitment for students was 
comparable to a 3 credit course. All of the projects required an extensive amount of analysis by the students groups to understand the customer's problems, and to help them define what type of solution should be developed by the student teams.

Instrument and Results

The survey consisted of 3 questions. The first two questions were multiple choice questions and the last question was open ended. The first question was designed to determine where students felt they experienced the greatest challenges during the semester long project.

Question 1. Which one of the following has presented you with the greatest challenges in completion of your Capstone project?

a. Using curricular/technical knowledge gained in your courses or learned independently to solve the problem

b. Dealing with communication problems, delays, different personalities, company specific constraints (policies, protocols, procedures), scope changes, or prioritization?

c. Internal capstone team issues

The results from this question can be seen in Figure 1. Students overwhelming reported that the greatest challenges were related to the working within a professional work environment. This is consistent with previous research that reports frustration with industry sponsored projects ${ }^{1}$.

Anecdotal evidence from the class also supports these results. Many students report difficulties with communications, coordination, policies, and delays.

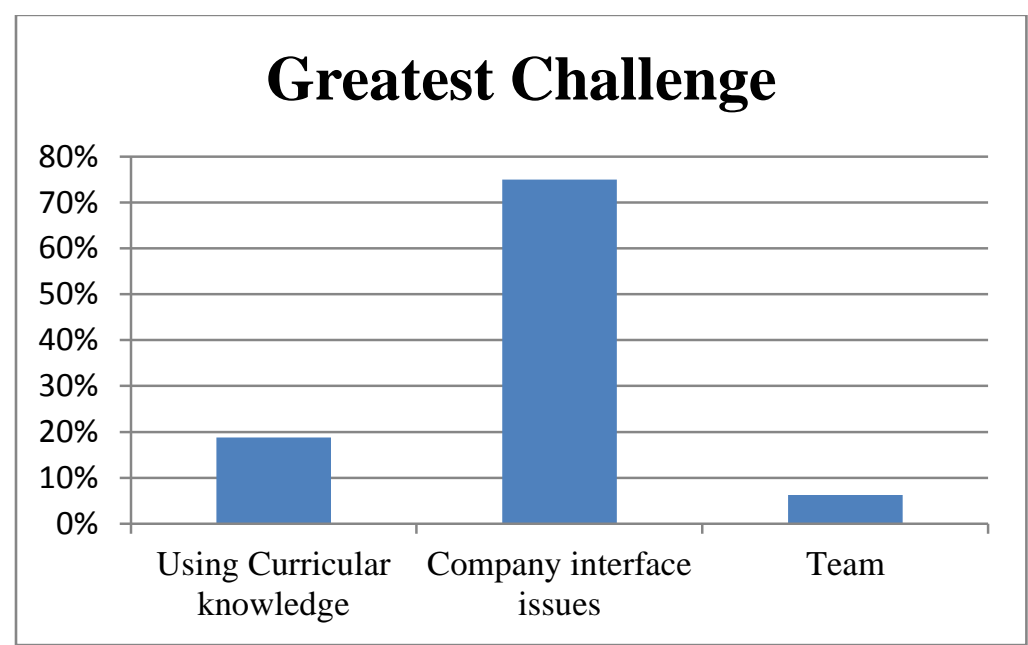

Figure 1: Question 1 results.

The second question on the survey was designed to determine where students felt they had gained the most knowledge during project completion.

Question 2. In which one of the categories do you believe you gained the most knowledge during the course of the capstone project?

a. Curricular/technical knowledge

b. Knowledge of how to effectively complete a project within an organization context 


\section{c. Knowledge of how to effectively work in teams}

Results from this question can be seen in Figure 2. Once again, students overwhelming reported greatest knowledge gain in professional work skills or soft skills. Just over $10 \%$ of the students reported primary knowledge gain in curricular knowledge. The results from this question may imply two different things. The first implication is that the projects themselves were representative of the curriculum and knowledge already gained in previous courses. Anecdotal evidence also supports this idea. Students reported in the course that they were surprised how well they were able to pull knowledge from some other courses already taken to solve the problems presented. The second implication is that the capstone experience consisted primarily of learning how to work with the company and its representatives to solve the problems presented.

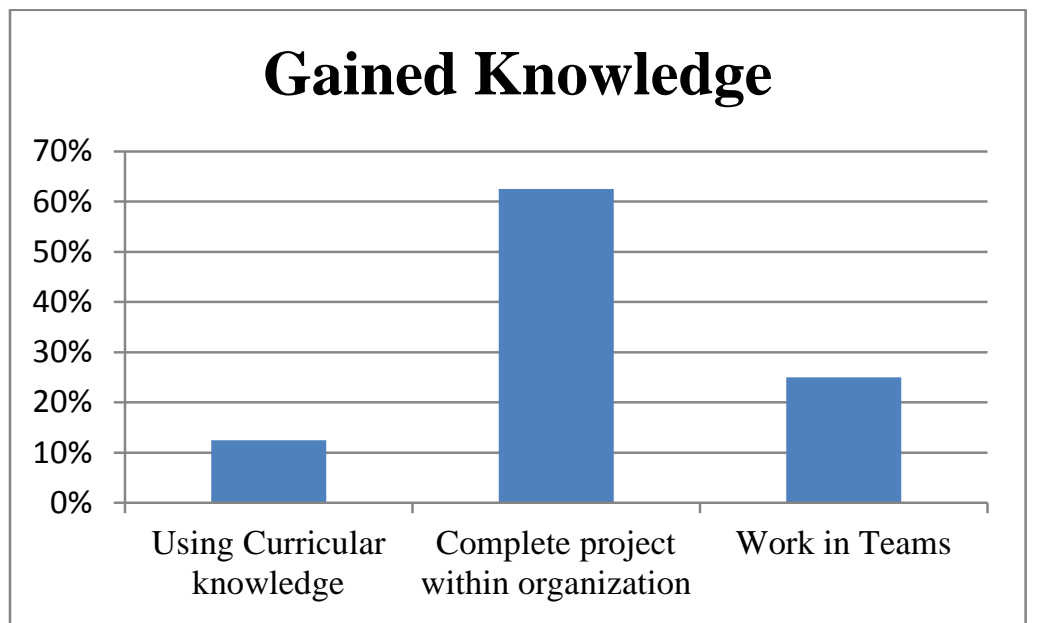

Figure 2: Question 2 results.

The last question on the survey was an open ended question designed to capture the primary learning experience that students found to be the most useful during the capstone experience. These answers were coded and categorized by the three categories of Professional Knowledge as described by Sheppard et al. ${ }^{10}$. The results can be seen in Figure 3.

Question 3. Tell us briefly about one learning experience that you had during your capstone project that you feel will help you in your future career.

Results from this question show that the majority of the comments made by students were related to professional practice. Many of the students had more than one comment. Very few of the students commented on learning new knowledge even though the project would have required most of the students to gain additional technical knowledge. Comments indicative of the nature and tone of the results were, "One thing I learned was how difficult it is to make a major change in an organization or business. People resist change."; "A problem in real-life is a lot harder than just a problem out of a book that has an actual answer."; "I feel the biggest learning experience came with the completion of the project as a team." 


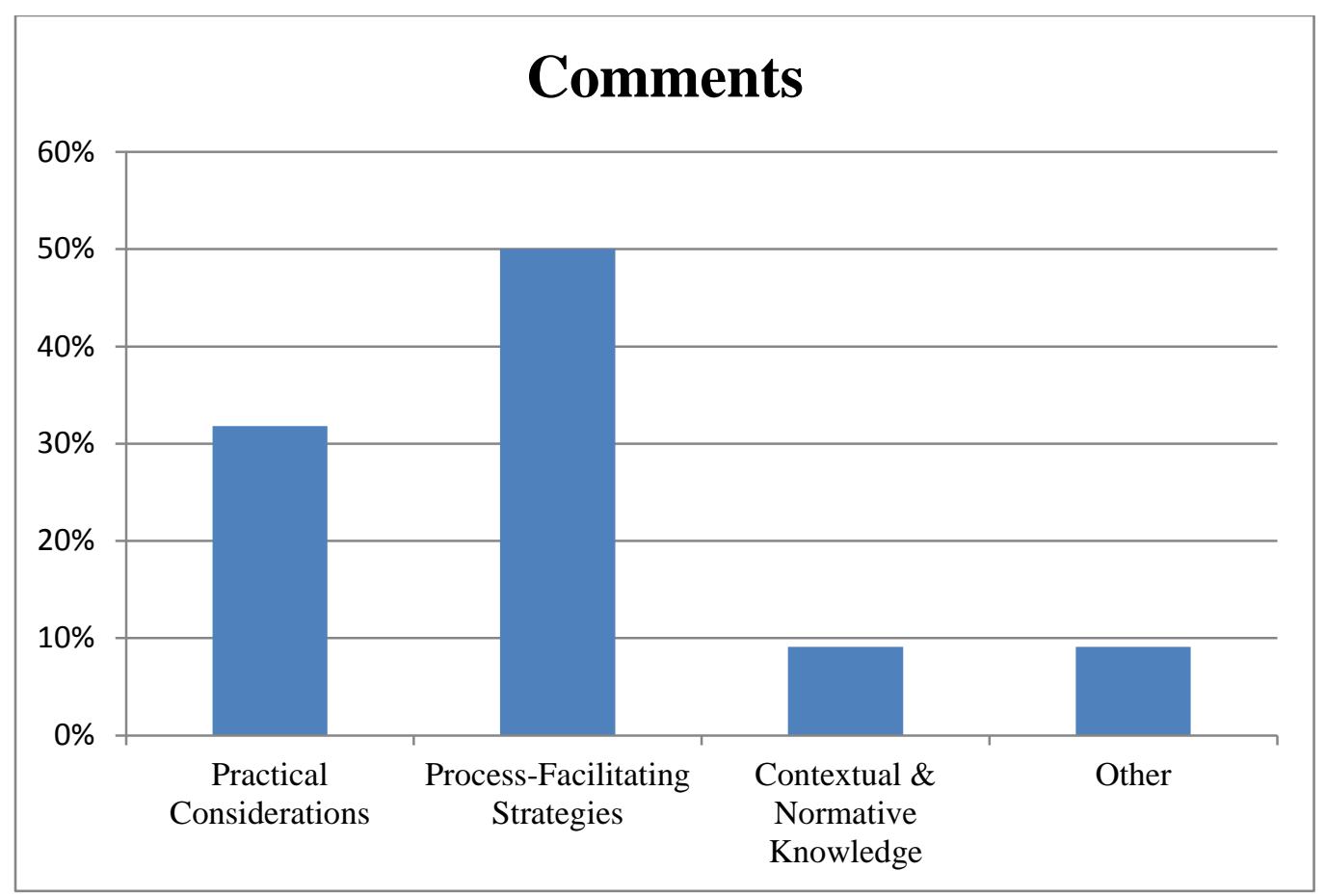

Figure 3: Question 3 results.

Results indicate that students were left with a definite awareness of the importance of professional or soft skills. Results also indicate that students have not only gained awareness but also learned strategies that will make them more successful in a professional work environment. Other comments include, "I learned that talking about a problem with a group of people can potentially give a lot of different solutions."; "Delegating people to complete tasks and relying on one another's information was a large concept that I learned."

Conclusions

Research indicates that professional or soft skills are important to the success of students in the work environment. The results of this study indicate that students do gain considerable knowledge and experience in professional or soft skills during the completion of an industry sponsored capstone project. The capstone course has certainly fulfilled its mission to "provide a capstone or integrating experience that develops student competencies in applying both technical and non-technical skills in solving problems",2. This study shows that industry sponsored projects are an effective method for providing these integrating experiences although it is unclear whether they have any advantages over other methods of developing students outcome. This study is limited due to its small sample size. Anecdotal evidence from other classes supports the results of this study, but it is expected that results will differ somewhat from year to year and based upon the projects selected for the course. There is also no evidence in this study that other methods are better or worse for developing soft skills in students than industry sponsored projects. Another limitation is that there was no evidence collected that measures the amount of soft skills learned in the capstone course. Future work will be done to determine the specific types of skills developed and the gains associated with industry sponsored projects. 
Lessons learned from this study include that industry sponsored projects have been instrumental to the development of professional skills of students. Placing students in a professional environment allows them learn how to work in that environment. The projects, however, must be carefully selected to provide challenges that are appropriately challenging, but, not overwhelming. The industry sponsor must be willing and able to spend the time necessary to support the project participants and keep the project moving in a productive direction. The instructor must ask questions and monitor progress on a continuous basis to ensure that the students continue to have a positive learning experience. Both the industry sponsor and the instructor must be open to scope changes to accommodate problems or changes that arise. There is extra work involved in the use of industry sponsored projects for capstone experiences however, the positive learning experiences are invaluable to student development.

\section{Bibliography}

1. Parsons, A.L. \& Lepkowska-White, E. 2009. Group projects using clients versus not using clients. Journal of Marketing Education. 31(2):154-159

2. ABET. 2013-14 Criteria for Accrediting Engineering Technology Programs. Retrieved Nov 1, 2013 from http://www.abet.org/DisplayTemplates/DocsHandbook.aspx?id=3150

3. Nguyen, H., McIntyre, C., \& Diab, M. 2005. Measuring learning performance of an engineering capstone course with respect to the ABET engineering criteria. Proceedings of the 2005 ASEE North Midwest Conference, Brookings, SD

4. Lillevik, S.L. 2004. Capstone design through cooperative learning. Proceedings of the 2004 ASEE Annual Conference \& Exposition, Salt Lake City, UT

5. Potter, L. \& Min, J. 2005. ABET outcome assessment in an industrial engineering capstone design course. Proceedings of the 2005 ASEE North Midwest Conference. Brookings, SD

6. Akili, W. 2008. Teaching capstone design for students in civil engineering: A partnership between academics and practitioners. Proceedings of the 2008 ASEE North Midwest Conference, Platteville, WI

7. Furtner, R.G. 2005. From subjective to objective: Using detailed rubrics for grading senior design proposals. Proceedings of the 2005 ASEE North Midwest Conference, Brookings, SD

8. Shuman, L.J., M. Besterfiled-Sacre, and J. McGourty. 2005. The ABET "professional skills" - Can they be taught? Can they be assessed? Journal of Engineering Education 94(1): 41-55

9. Rao, M.S. 2012. Myths and truths about soft skills. Training \& Development. May 2012, pp. 49-50

Pulko, S.H., \& Parikh, S. 2003. Teaching soft skills to engineers. International Journal of Electrical Engineering Education. 40(4): 243-254

10. Sheppard, S.D., Macatangay, K., Colby, A., \& Sullivan, W.M. 2008. Educating engineers: Designing for the future of the field. Jossey-Bass. San Francisco.

11. Pulko, S.H., \& Parikh, S. 2003. Teaching soft skills to engineers. International Journal of Electrical Engineering Education. 40(4): 243-254

12. Boyce, G., Williams, S., Kelly, A., \& Yee, H. 2001. Fostering deep and elaborative learning and generic (soft) skill development: The strategic use of case studies in accounting education. Accounting Education. 10(1):37-60 13. Biggs, J.B. 1989. Approaches to the enhancement of tertiary teaching. Higher Education Research and Development.8(1):7-25

14. Steinlicht, C. \& Garry, B. 2013. Systems learning within the context of subject learning. Proceedings of the 2013 ASEE Annual Conference \& Exposition. AC 2013-6951. Atlanta, GA

15. Bove, L.L. \& Davies, W.M. 2009. A case study of teaching marketing research using client-sponsored projects: Method, challenges, and benefits. Journal of Marketing Education. 31(3):230-239

16. Ray, J.L. 2003. Industry-academic partnerships for successful capstone projects. ASEE/IEEE Frontiers in Education Conference, Boulder, $\mathrm{CO}$

17. Heybruck, B., Thurman, L., \& Heybruck, W.F. 2011. Increasing broader industrial participation in engineering \& technical undergraduate programs. Proceedings of the 2011 ASEE Annual Conference \& Exposition, Vancouver, $\mathrm{BC}$ 
18. Roundhill, J. (2001). Working together works. Proceedings of the ASEE 2001 Engineering Deans Institute, Victoria, BC, Canada.

19. Jack, H. 2013. 2013 State of manufacturing education. Proceedings of the 2013 ASEE Annual Conference \& Exposition. Atlanta, GA

20. Transforming undergraduate education in engineering. Phase I: Synthesizing and integrating industry perspectives Workshop Report. 2013. American Society for Engineering Education. Retrieved from http://www.asee.org/TUEE_PhaseI_WorkshopReport.pdf

21. Palmer, S.R. 2000. Student responses to activities designed to develop generic professional skills. Journal of Professional Issues in Engineering Education and Practice. 126(4):180-185

22. Garry, B. (2013). Effect of previous experience and attitudes on capstone project achievement. Proceedings of the 2013 ASEE Annual Conference \& Exposition. AC 2013-6033. Atlanta, GA 